\title{
More than scepticism
}

\section{Baltimore}

As researchers from laboratories and universities throughout the United States lined up to announce their failure to achieve cold fusion, a late-night session of the American Physical Society (APS), in Baltimore last Monday, took on the atmosphere of a hanging party lacking only its intended victims - Stanley Pons and Martin Fleischmann.

Loud applause greeted the remark by Steven Koonin, of the University of California at Santa Barbara, that the heat supposedly generated in a palladium electrode was a sign of "incompetence, perhaps delusion" on the part of the University of Utah researchers.

More significant than the list of negative results were the explanations offered by some of the speakers for the disputed claims. The $2.2 \mathrm{MeV}$ gamma-rays offered by Pons and Fleischmann as evidence for the production of fast neutrons could, some speakers suggested, be due to radioactive decays of bismuth derived from naturally occurring radon, and the presence of helium- 4 in a few parts per million could result from contamination by laboratory air rather than fusion of deuterium.

But the centrepiece of Pons and Fleischmann's claim, that heat is produced in their electrolytic cells in amounts too large to be explained by purely chemical processes, was dissected by Nathan Lewis, of the California Institute of Technology, and W. Meyerhof, of Stanford University, who ascribed the energy generation to poor calorimetry and an inadequate accounting of the data.

By contrast, Steven Jones, of Brigham Young University, met with a polite but generally sceptical reception. His claim of nuclear fusion, signified by neutron emission at a very low rate, survived the evening mostly unscathed, because most of the experimenters reporting their results did not have neutron detectors of the same sensitivity. But J. Dickens, of Oak Ridge National Laboratory in Tennessee, put in a vote against Jones, saying that his own group had failed to find neutrons at a level nearly ten times below what the Brigham Young group has argued for.

A certain amount of enmity had been generated the previous week, when Pons and Fleischmann told the House Committee on Science, Space and Technology on 26 April that they were "sure as sure can be" that cold fusion worked. Chase Peterson, president of the University of Utah, suggested $\$ 25$ million as a reasonable amount of money for the federal government to spend on a scaling-up of bench-top fusion experiments.

At the same hearing, Jones made it clear that, although he believed in the reality of cold fusion, he saw it as an inter- esting piece of physics, not as a technology for energy production. By the time physicists such as Harold Furth, director of the Princeton University Plasma Physics Laboratory, were giving their sceptical testimony, most of the congressmen had left. The hearing nevertheless provided an opportunity for some committee members to praise the virtues of "small science", and applaud the invention of an American technology that will "change the face of the Earth".

But questions about the lack of confirmation by other scientists and the continued absence of a full published account of the work made several congressmen nervous of jumping in too soon with federal funds. To dispel such doubts, Ira Magaziner, a consultant to the University of Utah, listed half a dozen previous US inventions which had been brought to commercial fruition by the Japanese, and urged the committee to move now, even before the science was widely accepted.

Yet it is unlikely that any congressional initiatives will emerge while the scientific status of cold fusion changes daily. Robert Huggins, a materials scientist at Stanford University, was warmly received by the committee for his account of an experiment which seemed to confirm heat generation by cold fusion, but later flew to San Diego and into a more questioning audience when he described his results in full at a hastily organized session of a meeting of the Materials Science Research Society.

Huggins and his colleagues say they have observed temperature differences of up to $10^{\circ} \mathrm{C}$ between a cell containing deuterated water and an identical cell containing ordinary water, representing an excess energy in the deuterated sample of 15 to 40 per cent.

The secret of his success, Huggins said, lies in the elimination of hydrogen from the palladium electrode and the cell containing heavy water, by repeated melting and recasting of the electrode material and assembly of the apparatus in a glovebox filled with dry nitrogen. Regular hydrogen will readily pollute the experiment, he said, if introduced either as hydrogen occupying sites in the palladium matrix or as water from the atmosphere, which will be absorbed by the heavy water and preferentially hydrolysed at the palladium cathode.

This experiment, as well as the work of Pons and Fleischmann, was criticized at a fundamental level by speakers at the Baltimore meeting last Monday. Both Lewis and Meyerhof spoke of the difficulty of doing exact calorimetry in an open system which gives off gases and needs to be replenished with fresh electrolyte. The rate of energy generation is derived from a measurement of the temperature of a working cell, and it is in this measurement that experimental niceties can prove overwhelming.

Neither Huggins nor Pons and Fleischmann attempted to stir the electrolyte in their cells, which suggests that temperature gradients can develop, and means that different temperatures can be due either to different energy generation rates or more simply to different placements of the thermometer in the cell.

Both Lewis and Meyerhof had attempted to reproduce the exact cell construction used by Pons and Fleischmann. They did this by examining whatever photographs and diagrams they could find, and deriving a scale from the size of Pons's hand. Both Lewis, by demonstration, and Meyerhof, by calculation, then showed that 'energy generation' of the magnitude claimed could arise because the temperature distribution in the cell was far from uniform, and the thermometer placement gave rise to a misleading heat output.

The problem was aggravated, Lewis said, because the table of results given by Pons and Fleischmann listed energy outputs not as a percentage of the total energy supplied, but as a percentage of the calculated and strictly chemical heat output. The energy discrepancies, as found by Lewis by back-calculation from the published data, are not so startling in magnitude.

In the experiments done by Lewis and his colleagues, the electrolytic cell was stirred to maintain a uniform temperature, and was also kept at a constant temperature by means of a resistive heater: if the electrode voltage was reduced, the heater was turned up by a measured amount to keep the total heat supply the same. Thus the calorimeter had constant internal calibration. In a still-continuing series of experiments and comparisons, Lewis reported that they had found no anomalous heat generation to a level of 6 per cent, the emprically estimated accuracy of their device.

At the end of the session at Baltimore, physicists were left with the comfortable feeling that fusion was dead, except for small effects of the sort claimed by the Brigham Young group. If, and how quickly, chemists come to the same conclusion is not yet apparent.

David Lindley

\section{Corrections}

THE statement in our article on 27 April (338, $702 ; 1989)$ that the Brigham Young group had not replicated their measurement with $\mathrm{H}_{2} 0$ is incorrect. Such a replication is described in their original article $(338,737 ; 1989)$. A News story in the 20 April issue of Nature (338, 605; 1989 ) incorrectly refers to a press conference at Texas A \& M on 10 March: this should be 10 April. And reports of an experiment at the University of Moscow were received on 12 April, not 12 March. Keith Johnson of MIT was incorrectly referred to as Keith Jones. 